ИЗВЕСТИЯ АКАДЕМИИ НАУК ЭСТОНСКОИ ССР. ТОМ 29

ГЕОЛОГИЯ. 1980. № 4

\title{
К МИКРОФИТОЛОГИЧЕСКОЙ ХАРАКТЕРИСТИКЕ СРЕДНЕ- И ВЕРХНЕКЕМБРИЙСКИХ ОТЛОЖЕНИЙ СЕВЕРО-ЗАПАДНОЙ ЧАСТИ ВОСТОЧНО-ЕВРОПЕЙСКОЙ ПЛАТФОРМЫ
}

Существенным пробелом в исследовании биостратиграфии кембрийских отложений Восточно-Европейской платформы является слабая изученность акритарх среднего кембрия, сведения о которых пока весьма фрагментарны и во многом противоречивы. Совершенно отсутствуют сведения о составе акритарх верхнего кембрия. Это в существенной степени препятствует разработке очень актуальных в настоящее время схем корреляции «немых» в фаунистическом отношении терригенных толщ, развитых в виде сплошного чехла выше толщи «синих глин» (балтийская серия) и ниже подошвы ордовикской системы по всей северо-западной части этого огромного региона.

Новые данные по микрофитологии кембрийских отложений юга Балтийской синеклизы, северо-западного склона Мазурско-Белорусской антеклизы, южного склона Балтийского щита и Московской синеклизы позволяют уточнить существующие -представления (Палеонтология ..., 1979; Решения..., 1978) о вертикальном распространении акритарх на переходе от нижнего кембрия к среднему, определить состав среднекембрийских комплексов акритарх, развитых за пределами Балтийской синеклизы (уже довольно хорошо изученной), и впервые привести список акритарх из отложений предположительно верхнекембрийского возраста. Рассмотрим некоторые наиболее интересные разрезы (см. рисунок).

В западных районах Литовской ССР (юг Балтийской синеклизы) впервые пробурено несколько скважин с полным отбором керна. Стали доступными для исследователей слои на уровне верхов нижнего и низов среднего кембрия (вирбалисская и кибартайская свиты). В нижней части кибартайской свиты (скв. Геняй-I, гл. 1879-1885 м; скв. Горайняй-I, гл. 2080-2085 м) установлен смешанный комплекс акритарх, особенностью которого является присутствие совместно с обычными для данной свиты среднекембрийскими акритархами (Baltisphaeridium pseudofaveolatum Friedrichsone, Micrhystridium notatum Volk., M. obscurum Volk.) большого количества видов, доминирующих в нижнем кембрии. В среднекембрийских отложениях эти виды установлены впервые. Это Micrhystridium lanatum Volk., M. dissimilare Volk., Estiastra minima Volk., Deunffia dentifera Volk., D. flagellata Jank., Ovulum lanceolatum Jank., Aranidum confusum Jank. Таким образом, установлен факт присутствия в несомненно среднекембрийских отложениях целого ряда, казалось бы, «типично нижнекембрийских» акритарх. Судя по всему, в определенных фациях низов среднего кембрия могут быть встречены комплексы акритарх, близкие по составу к нижнекембрийским. 
Новая глубокая скв. Аукштеи Панеряй (далее А. Панеряй) пробурена в черте г. Вильнюса (северо-западный склон Мазурско-Белорусской синеклизы). В интервале $356-375$ м этой скважины вскрыта песчаная лакайская свита (рисунок), возраст которой в других разрезах по присутствию в ее породах некоторых характерных для нижнего кембрия видов определен первоначально как вергальско-раусвеский (Янкаускас, 1974). Новая информация, полученная при микрофитологическом исследовании керна А. Панеряй, позволяет существенно уточнить возраст лакайской свиты.

В ее основании (гл. 372 м) установлены многочисленные акритархи, в большинстве случаев представленные обычными для нижнекембрийских отложений Балтийской синеклизы видами: Micrhystridium lanatum Volk., M. dissimilare Volk., Estiastra minima Volk., Ovulum saccatum Jank., O. lanceolatum Jank., Baltisphaeridium dendroideum Jank. Однако совместно с ними обнаружены единичные Baltisphaeridium pseudofaveolatum Friedrichsone - вид-индекс кибартайского горизонта низов среднего кембрия. Из прослоя глин в 1 м выше по разрезу (гл. 371 м) выделены многочисленные Multiplicisphaeridium lancarae $\mathrm{Cr}$. et D., возраст которых несомненно среднекембрийский (Cramer, Diez, 1972), а также массовые Aranidium confusum Jank., что характерно для низов кибартайской свиты запада Литовской ССР, и некоторые другие. C глубины 362 м появляются Cymatiosphaera ovillensis $\mathrm{Cr}$. et D., характерные для среднего кембрия Испании (Cramer, Diez, 1972).

В связи с приведенными данными возраст лакайской свиты в районе Вильнюса должен быть отнесен к верхам айсчяйской серии (кибартайский горизонт), а не к ее нижней части, как это предлагалось автором раньше (Янкаускас, 1974). Уточнение возраста лакайской свиты данного регнона вызывает необходимость ревизии представлений о вертикальном распространении и таксономии описанных автором ранее акритарх.

Так, вид Multiplicisphaeridium vilnense (Jank.) описан из лакайской свиты соседней (также в черте г. Вильнюса) скв. Яченис-299 в качестве нижнекембрийского (Янкаускас, 1976). Однако приведенные выше новые данные побуждают автора перевести его в число среднекембрийских форм. Одновременно выяснилось, что морфологически идентичные формы описаны из среднекембрийских отложений Испании под названием Multiplicisphaeridium lancarae (Cramer et Diez, 1972). K сожалению, журнал, где эта форма описана, не была доступна автору в момент выделения $M$. vilnense. В данной статье название этого вида рассматривается как поздний синоним $M$. lancarae. Другой вид автора Cymatiosphaera favosa Jank. (Янкаускас, 1976) — является поздним

Средне- и верхнекембрийские акритархи Восточно-Европейской платформы. Увел. $1000 \times$.

Фиг. 1, 2, 3, 6. Multiplicisphaeridium lancarae Cramer et Diez. 1, 2 и 6 - скв. Толбухино-1, пл. 2150,7 м. ЛитНИГРИ, преп. 17-1-2150, экз. $1-3 ; 3-$ скв. Заречье, гл. 162 м, ЛитНИГРИ, преп. 15-101-162, экз. 1. Фиг. 4. Alliumella baltica Vand. р. Тосна, средняя часть ижорской свиты, ЛитНИГРИ, преп. 15-52-15/10, экз. 2. Фиг. 5, 7. Multiplicisphaeridium martae Cramer et Diez. 5 - скв. Толбухино-1, гл. 2150,7 м, ЛитниГРИ, преп. 17-1-2150, экз, 4; 7 - скв. Заречье, гл. 162 м, ЛитНИГРИ, преп. 15-101-162, экз. 2. Фиг. 8. Aranidium confusum Jank. Там же, экз. 3. Фиг. 9. Vulcanisphaera aff. africana Deunff. Скв. Толбухино-1, гл. 2150,7 M, ЛитНИГРИ, преп. 17-1-2150, экз. 6. Фиr. 10. Cymatiosphaera sp. nov. Скв. Толбухино-1, гл. 2150,7 м, ЛитНИГРИ, прел. 17-1-2150, экз. 7. Фиг. 11, 12. Cymatiosphaera ovillensis Cramer et Diez. 11 - скв. Толбухино-1, гл. 2150,7 м, ЛитНИГРИ, преп. 17-1-2150, экз. $5 ; 12-$ р. Тосна, средняя часть нжорской свиты, ЛитНИГРИ, преп. 15-52-15/10, экз. 1. 

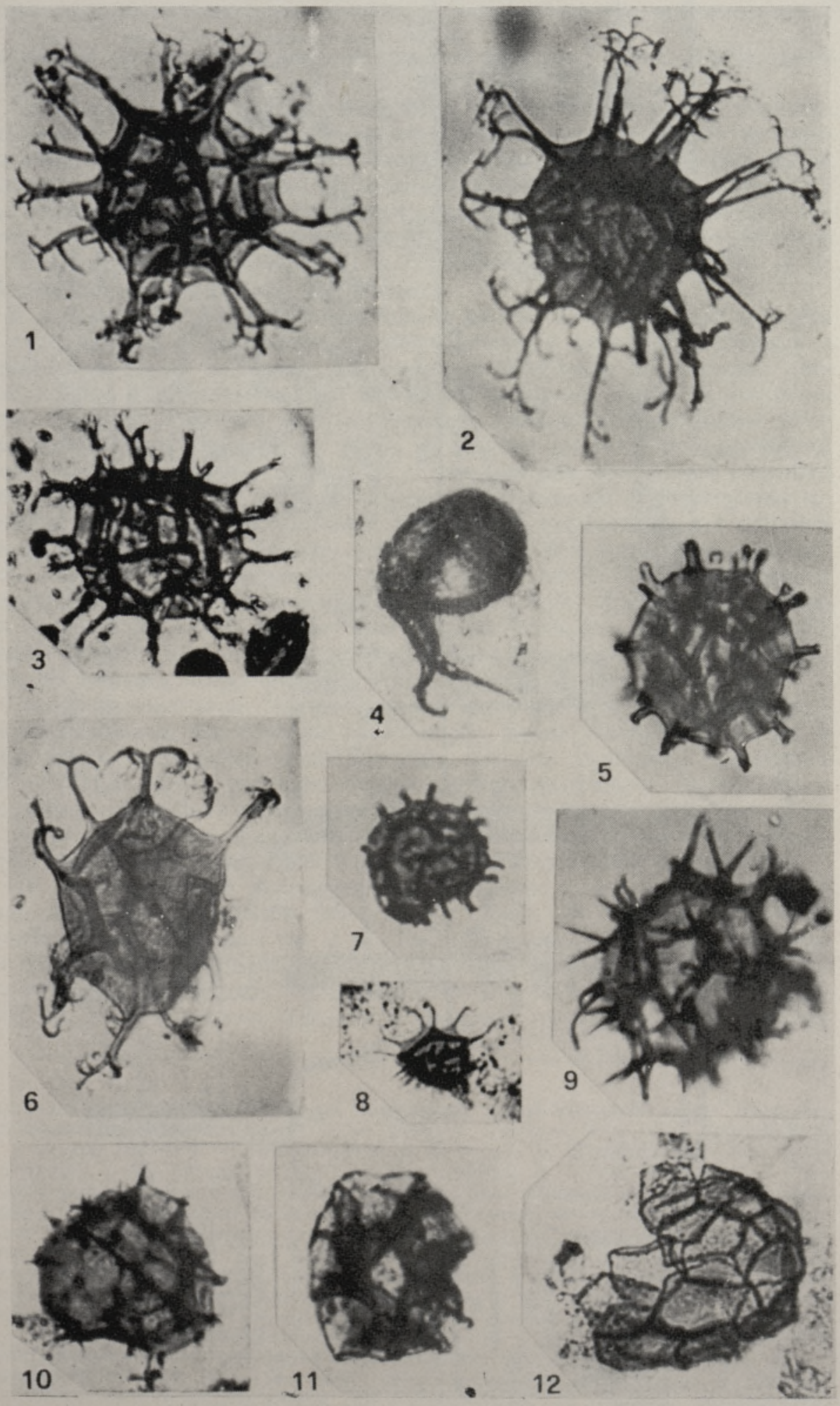


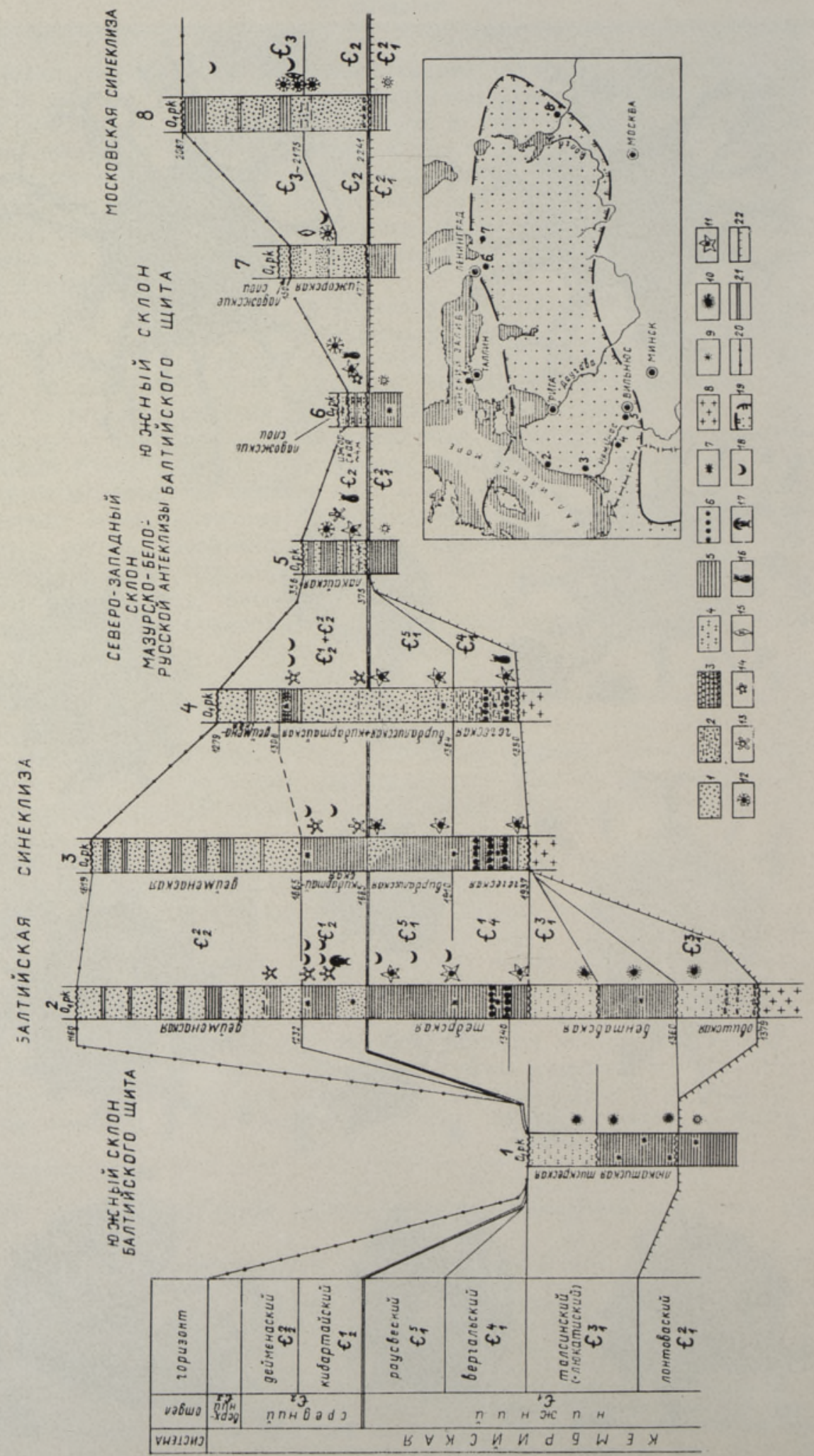


синонимом описанного в той же работе (Cramer, Diez, 1972) вида C. ovillensis.

Лакайская свита района Вильнюса по литологическому составу, положению в разрезе и микрофитологической характеристике во многом аналогична ижорской свите Ленинградской области (южный склон Балтийского щита). Помимо форм нижнекембрийского облика (Янкаускас, 1974) в породах последней установлены также виды, несомненно более молодые. Это редкие экземпляры Multiplicisphaeridium lancarae Cr. et D. (разрез по р. Ижора) и Cymatiosphaera ovillensis $\mathrm{Cr}$. et D. и Aranidium confusum Jank. (р. Тосна).

В разрезе скв. Заречье в восточной части Ленинградской области на глубине 162 м установлены многочисленные акритархи. Наряду с формами, которые по новым данным в кембрийских отложениях следует считать транзитными (это Ovulum lancealatum Jank., O. saccatum Jank., Deunffia flagellata Jank., Aranidium sp.), многочисленными Multiplicisphaeridium lancarae Cr. et D., M. martae Cr. et D. и единичными Cymatiosphaera ovillensis $\mathrm{Cr}$. et D., обычными для отложений среднего кембрия (см. таблицу), встречены редкие Leiofusa sp. и Priscogalea sp. Появление первых представителей этих родов характерно для отложений верхнего кембрия Англии (Potter, 1974). Это дает основание думать, что в составе ижорской (саблинской - по Л. Б. Рухину) свиты присутствуют слои верхнекембрийского возраста. Кроме перечисленных выше форм здесь обнаружены также Pirea sp. и Poikilofusa aff. squama Deunff., широко распространенные в отложениях нижнего ордовика, но, видимо, появляющиеся в отдельных разрезах и ниже.

Наконец, некоторые новые данные по разрезу скв. Толбухино-1 (восточная часть Московской синеклизы). Выше балтийской серии и ниже слоев с первыми граптолитами раннего ордовика (интервал $2087-2241$ м) здесь залегает толща светлых кварцевых песчаников с прослоями зеленовато-серых глин. Возраст ее определяется по-разному, от среднего кембрия до нижнего ордовика включительно (Балашова, 1963; Чагаев, Никашин, 1972; Умнова, 1974; Шестакова и др., 1976).

На глубине 2171,5 м автором установлены многочисленные акритархи Multiplicisphaeridium lancarae Cr. et D., M. martae Cr. et D., Cymatiosphaera ovillensis Cr. et D., Ovulum saccatum Jank., O. lanceolatum Jank., Deunffia flagellata Jank., Aranidium sp., Pirea sp., Poikilofusa aff. squama Deunff., Vulcanisphaera aff. africana Deunff., Priscogalea sp. Этот комплекс, близкий в видовом отношении к описанному

Корреляции разрезов пастбалтийских отложений северо-западной части ВосточноЕвропейской платформы. Разрезы: 1 - район г. Таллина; 2 - скв. Вергале-45 и $-49 ; 3-$ скв. Геняй; 4 - скв. Кибартай-22; 5 - скв. А. Панеряй; 6 - обнажение на р: Ижора у дер. Федоровское; 7 - скв. Заречье; 8 - скв. Толбухино-1. Расчлененне разрезов дано в соответствии с материалами обзорной монографии (Стратиграфия..., 1979). Условные обозначения: 1 - преимущественно песчаники, 2 - песчаники с прослоями глинистых пород, 3 - переслаивание песчаников и глин (аргиллитов), 4 - алевролиты, 5 - глины (или аргиллиты), 6 - прослои железистых песчаников и оолитовых железняков, 7 - глауконит в породе, 8 - кристаллический фундамент, 9 - акритархи Granomarginata prima, 10 - акритархи Baltisphaeridium. cerinum и B. orbiculare, 11 - акритархи Estiastra minima и Micrhystridium lanatum, 12 - акритархи Multiplicisphaeridium lancarae, 13 - акритархи Baltisphaeridium pseudofaveolatum, 14 - акритархи Lophomarginata glumacea и 'L. corollata, 15 акритархи Poikilofusa, 16 - массовые скопления акрнтарх Aranidium и Ovulum, 17 - среднекембрийские трилобиты, 18 - брахиоподы, 19 - ареал распространения среднекембрийских отложений, 20 - подошва ордовикской системы, 21 граница между нижшим и средним отделами кембрийской системы, 22 - подошва постбалтийских отложений. 
из скв. Заречье Ленинградской области, определяет возраст вмещающих отложений как верхний кембрий. Близкий состав акритарх установлен и выше, на глубине 2155 и 2150 м. Лишь на глубине 2087 м впервые в разрезе появляются типично тремадокские акритархи, представленные родами Acanthodiacrodium, Lophodiacrodium, Dazydiacrodium, Ooidium, Veryhachium, Polygonium, Cymatiogalea и др.

К среднему кембрию в разрезе скв. Толбухино-1 могут быть отнесены слои, залегающие глубже $2174-2178$ м. Здесь не обнаружено верхнекембрийских форм и присутствуют лишь характерные для среднего кембрия Multiplicisphaeridium lancarae Cr. et D., M. martae $\mathrm{Cr}$. et D., Cymatiosphaera ovillensis Cr. et D.

Это подтверждается также находкой кранидия трилобита в той же скважине на глубине 2174,8 м, который, по К. Лендзён (Варшава), относится к Agnostus subsulkatus West., характеризующему вмещающие отложения как верхи среднего кембрия.

Приведенные данные хорошо согласуются с мнением о присутствии в составе обсуждаемой толщи слоев верхнекембрийского возраста (Балашова, 1963; Чагаев, Никашин, 1972; Шестакова и др., 1976) и дают основание говорить о необходимости строгой ревизии коллекций акритарх некоторых исследователей (Умнова, 1974 и др.), ранее сообщавших о находках в ней видов ордовикского возраста.

Новые данные и изложенные здесь соображения позволяют по новому проводить корреляцию постбалтийских отложений кембрия северозападной части Восточно-Европейской пілатформы.

\section{Л И Т Е Р А Т Р Р А}

Бал а шов а Е. А. Первая находка верхнекембрийских трилобитов на Русской платформе. - Вест. Ленингр. ун-та, сер. геол. и геогр., 1963, 12, 126-128.

Палеонтология верхнедокембрийских и кембрийских отложений Восточно-Европейской платформы. М., 1979.

Решения Межведомственного регионального стратиграфического совещания по разработке унифицированных стратиграфических схем Прибалтики, 1976 г. Л., 1978.

Стратиграфия верхнедокембрийских и кембрийских отложений запада Восточно-Европейской платформы. М., 1979.

У м н в в Н. И. Комплексы акритарх ордовика и силура северной и западной частей Русской платформы. - Палинология протерофита и палеофита. Тр. III Междунар. палинол. конференции. М., 1974, 33-38.

Ч а га ев А. Я., Никашин Э. С. К вопросу о границе кембрия и ордовика в центральной части 'Московской синеклизы. - Экспресс информация. Нефтегазовая геология и геофизика, $1972,7,10-16$.

Шест ка в а“ М. Д., Кле вц в а А. А., С у в оров а Н. П. К стратиграфии кембрия Московской синеклизы. - Изв. АН СССР, сер. геол., 1976, 12, 58-66.

Я н к у ск а с Т. В. Палеонтологическое обоснование геологического возраста ижорской свиты кембрия Русской платформы. - Изв. АН СССР, сер. геол., 1974, $1,85-91$.

Я н к а уск а с Т. В. Новые виды акритарх из нижнего кембрня Прибалтики. - Сंтратиграфия и палеонтология нижнего и среднего кембрия СССР. Новосибирск, 1976, $187-192$.

Cramer, F. H., Diez de Cramer, M. d. C. R. Acritarchs from the Upper Middle Cambrian Ovillo formation of Leon, North-western Spain. - Rev. Esp. de Micropaléontol., 1972, Num. extraord., Décembre, 39-50.

Potter, T. L. British Cambrian acritarchs. A Preliminary Account. - Rev. of Palaeobot. and Palynol., 1974, 18, 1-2, 61-62. 


\section{T. JANKAUSKAS}

\section{IDA-EUROOPA PLATVORMI LOODEOSA KESK- JA OLEMKAMBRIUMI MIKROFUTOLOOGIAST}

On esitatud Balti sünekliisist itta jääva ala baltijärgse kambriumi kivimite mikropaleontoloogilise (akritarhid) uurimise tulemused ning saadud andmete alusel täiendatud keskkambriumi akritarhide loetelu, revideeritud liikide stratigraafilist levikut ja täpsustatud vaadeldava settekeha korrelatsiooni Balti sünekliisi kambriumi läbilõikega.

\section{T. JANKAUSKAS}

\section{ON THE MICROPALAEONTOLOGICAL CHARACTERISTIC OF THE MIDDLE AND UPPER CAMBRIAN IN THE NORTH-WEST OF THE EAST-EUROPEAN PLATFORM}

The sedimentary sequence lying between the claystones of the Baltic series and the Ordovician beds in the region east from the Baltic syneclise has been micropalaeontologically (acritarchs) studied in some boreholes (see the Figure). The above-mentioned strata are represented by light-coloured sandstones and coarse-grained siltstones with intercalations of clayey rocks (columns $5-8$ in the Fig.). The great majority of the acritarchs existing in the strata, such as Micrhystridium lanatum Volk., M. dissimilare Volk., Estiastra minima Volk., Deunffia dentifera Volk., D. flagellata Jank., Ovulum lanceolatum Jank. and $O$. saccatum Jank. are widely distributed in the Lower Cambrian (excluding the Baltic Series). The occurrence of Baltisphaeridium pseudofaveolatum Fridrichsone, Aranidium confusum Jank., Multiplicisphaeridium lancarae Cr. et D., Cymatiosphaera ovillensis $\mathrm{Cr}$. et $\mathrm{D}$., which up to the present are khown from Middle Cambrian deposits, allow to distinguish the Middle Cambrian deposits (Fig.) in the studied sequence. The acritarch assemblages in the upper part of two boreholes (Zarechie 7, Tolbukhino 8), containing some species of Leiofusa, Priscogalea, Pirea, Poikilofusa and Vulcanisphaera showed that the Upper Cambrian is preserved sporadically on the EastEuropean platform. 